\title{
MURCHIDAT: RENACIMIENTO ISLÁMICO FEMENINO COMO CONTROL ESTATAL DEL DISCURSO RELIGIOSO EN MARRUECOS
}

\author{
MARIVÍ PÉREZ MATEO \\ Universidad Autónoma de Madrid
}

Recibido: 17/07/2015

Aceptado: 22/07/2015

\section{Resumen}

En este artículo se plantea cómo el programa de formación a estudiantes universitarias como murchidat, guías religiosas femeninas, que el estado marroquí ha ideado y codificado desde 2004, viene a sacar a la luz una tradicional transmisión del Islam por parte del género femenino y a revolucionar un estamento masculino como son las jerarquías o estructuras de la religión islámica. La formación y contratación como funcionarias de las nuevas guías religiosas otorga nuevas posibilidades laborales y cierta emancipación a través de la religión a jóvenes estudiantes creyentes, las transforma en líderes comunitarias cuya misión será la de transmitir un islam moderado y modelado estratégicamente desde el Ministerio de Asuntos Religiosos para controlar el discurso religioso y la radicalización. También se analizan en el texto la voz de las nuevas guías mostrando las similitudes de su discurso con los conceptos del feminismo islámico actual y se plantea cómo el reclutamiento de mujeres por parte de la administración marroquí puede responder a un movimiento de reislamización de la sociedad marroquí a través de un feminismo islámico de Estado.

Palabras clave; feminismo islámico, guías religiosas femeninas, murchidat.

\begin{abstract}
This article describes the training program for college students to become murchidat, female religious guides. The Moroccan state has developed and codified this new category since 2004, showing a traditional transmission of Islam by female and shaking the male establishment of the structures of the Islamic religion. The training and recruitment as officials of the new religious guides provides new job opportunities
\end{abstract}


and a certain emancipation through religion to young believers students, transformed into community leaders whose mission is to convey a moderate Islam that has been strategically shaped by the Ministry of Religious Affairs to control religious speech and radicalization. Also it is shown in the text the voice of the new women religious guide showing the similarities of their speech to the concepts of the current Islamic feminism. Finally, it is proposed as the recruitment of women by the Moroccan administration can respond to a movement of re-Islamization of Moroccan society through an Islamic state feminism.

Keywords: Islamic feminism, women religious guide, mourchidates. 


\section{Introducción}

En 2004, el estado marroquí comenzó a impartir una formación reglada destinada a estudiantes graduadas universitarias con la que se convertirían en murchidat ${ }^{1}$, funcionarias de la administración encargadas de formar y educar desde las mezquitas a otras mujeres. Esta nueva corriente de pedagogía islámica a mujeres se engloba dentro de las reformas del campo religioso emprendidas por la monarquía, desde que el actual rey Mohamed VI accediera al trono en 1999.

El objetivo de este artículo es analizar el modo en que el programa estatal de formación a estudiantes universitarias como murchidat, ideado y codificado por el gobierno marroquí en las últimas décadas, viene a revolucionar o sacar a la esfera pública una tradicional transmisión del islam por parte de las mujeres, así como otorgar posibilidades laborales y cierta emancipación a través de la religión a jóvenes estudiantes creyentes, transformándolas en líderes comunitarias y modificando el hasta entonces masculino ámbito de las jerarquías o estructuras de islam marroquí. Estas figuras están llamadas a tener relevancia dentro y fuera de la mezquita, en hospitales y prisiones, teniendo como misión principal transmitir un islam moderado y modelado estratégicamente desde el Ministerio de Asuntos Religiosos para controlar los discursos religiosos y la radicalización (Rausch).

Este trabajo es un extracto esencial de la tesis doctoral en curso sobre el papel de la mujer en la transmisión del islam. Metodológicamente nos acercamos, específicamente, al tema de este artículo, la figura de la murchida en Marruecos, tras la exploración bibliográfica de fuentes documentales primarias, recursos electrónicos online, noticias periodísticas, audiovisuales y entrevistas emitidas en diferentes medios de comunicación. La escasez de trabajos académicos inéditos sobre esta nueva categoría funcionarial y su formación nos hizo plantearnos la necesidad de realizar un trabajo de campo en Rabat que proporcione originalidad y visibilidad a nuestra investigación

1. En este artículo utilizaremos la transcripción del termino en árabe مرشندة, murchida en singular o murchidat en plural para referirnos a la figura femenina de las guías religiosas o predicadoras. Su equivalencia masculina es murchid y en plural murchidin. 
académica. Así, en este artículo se recoge la síntesis del trabajo realizado en la capital marroquí durante una estancia de investigación realizada en el mes de octubre del año 2014. Se concertaron varias entrevistas en la sede del Ministerio de Asuntos Religiosos, así como en la institución académica superior Dar al-Hadiz. Las informantes en la institución académica fueron cinco estudiantes inscritas en la promoción 2014-2015 de la capacitación de murchida. La entrevista grupal de una hora de duración y de contenido abierto se realizó en árabe y ha servido para extraer las conclusiones aquí expuestas. En la misma institución, también se entrevistó al director y al jefe de estudios y se recogieron los materiales inéditos, en árabe, que se exponen a continuación.

Del mismo modo, en el artículo planteamos tres hipótesis. La primera de ellas, es considerar el movimiento de las murchidat como una corriente de pedagogía islámica a mujeres que dentro del campo de la educación podría considerarse como incipiente hacia una emancipación de la condición social de las mujeres en el mundo árabe islámico. Por tanto, podríamos hablar de un movimiento liberador y de emancipación a través del conocimiento de la religión (Ali, 2012). Por otra parte, proponemos que en un estado donde la monarquía marroquí ostenta no sólo la máxima autoridad política del país, sino también la religiosa con el título de Emir o Comendador de los Creyentes (Darif), y que ha ideado el programa de formación a jóvenes estudiantes con la generación de esta nueva élite religiosa femenina puede, a su vez, ser el factor desencadenante de una suerte de movimiento de subversión, emancipador y liberador femenino con conceptos cercanos al feminismo islámico. Por último, con el reclutamiento de mujeres formadas en ciencias islámicas en las estructuras administrativas religiosas marroquíes, su reconocimiento y publicidad como nuevas autoridades religiosas, asistimos a una cierta feminización del Estado y esto a su vez puede propulsar cambios en las condiciones sociales de la mujer marroquí (Desrues y Moreno Nieto).

En el artículo damos la voz a las mujeres que participan de esta formación, tomando como base de la investigación el análisis emic de las informantes, del discurso de las estudiantes aspirantes a murchidat, en informaciones conseguidas a través de las entrevistas realizadas en el trabajo de campo dentro del Dar al-Hadiz al-Hassaniyya ${ }^{2}$, la institución encargada de formar a las nuevas autoridades religiosas femeninas. De sus palabras extraemos las ideas que podrían asimilarse a los conceptos utilizados en el movimiento del

2. En árabe دار الحديث الحسنية. La institución fue creada por el padre del actual monarca, Hassan II en 1968 para la formación de ulemas. Su composición y propósito se recoge en el dahir, texto legislativo, del 6 de agosto de 1968 extraído de la página de internet: < http://www.edhh.org >>, consultada el 13-07-2015. 
feminismo islámico como son el de justicia social, estrictamente en el sentido del conocimiento y que plantea las relaciones de género basadas en la ética coránica o el principio de igualdad divina. De este modo, contribuimos a la deconstrucción de la idea de los estudios académicos feministas occidentales de que la tradición islámica es, en sí misma, contraria a los propios intereses de las mujeres que los componen y que por tanto, los nuevos movimientos islámicos no ofrecen aparentemente atisbos de libertad a la agencia social o capacidad de acción femenina (Mahmood, 2008, 2011).

\section{La nueva autoridad religiosa femenina: murchida dinnya o guía espiritual}

La mujer transmisora del saber islámico no es una figura nueva en la tradición islámica sino que existen innumerables ejemplos de personajes femeninos religiosos que han pasado a la historia, así como movimientos históricos y/o actuales que muestran cómo las mujeres pueden ser líderes, formadoras, educadoras y predicadoras, tanto en la esfera pública como privada de la religión islámica. Así murchidat como murchidat dinnya, guías espirituales o religiosas, waidhat, predicadoras o alimat, mujeres sabias en religión, se encuentran en todas las sociedades árabe islámicas y es también notable su presencia a nivel transnacional entre la comunidad musulmana inmigrada.

El programa de murchidat no se considera novedoso en sí mismo ya que siempre ha habido mujeres guías espirituales que voluntariamente se afiliaban a mezquitas y centros regionales religiosos en las tareas de predicación, según un informe del Instituto Danés de Estudios Internacionales (El Haitami, 2013). También se considera, en este documento, el programa formativo como un instrumento para legitimar la figura del rey como Emir de los Creyentes, propagar un modelo de islam moderado «a lo marroquí» para luchar contra los integrismos. La participación de la mujer en el aparato burocrático estatal y su cobertura mediática internacional es interpretado en el informe como medidas para conformar una imagen hacia el exterior del estado marroquí como una nación democrática que realiza esfuerzos en la lucha contra el terrorismo yihadista (El Haitami, 2013).

Sin duda, los ejemplos de «liderazgo» femenino en la tradición islámica se encuentran en diferentes contextos. Desde las activistas feministas y revolucionarias que a partir de la década de los 90 del pasado siglo dirigen la oración del viernes en congregaciones mixtas en Sudáfrica y Norte América como Amina Wadud, a intelectuales críticas con la lectura patriarcal de los textos islámicos, como Asma Lamrabet en Marruecos, o promotoras de mezquitas exclusivas para mujeres como en ciertos lugares de China (Bano y Kalmbach). 
No obstante, con la muestra y explicación de estos modelos no pretendemos más que ofrecer algún ejemplo del posible papel protagonista y de liberación de la agencia femenina, que también podría verse en el movimiento de las murchidat en Marruecos y, a partir de ello, volver a plantear una pregunta clave, ya expuesta desde las teorías del feminismo, que es cómo deben los temas de especificidad histórica y cultural informar tanto del análisis como de la política de cualquier proyecto feminista. Los esfuerzos académicos de la teoría feminista han dejado relativamente inexplorada la diferencia religiosa en sí misma y aunque hayamos encontrado la diferenciación amplia entre los movimientos feministas en contextos occidentales y otras especificidades ya sea históricas, étnicas o geográficas, como feminismos negros o los llamados feminismos del Tercer Mundo (Mohanty, 1991, 2008), dentro del discurso del islam es quizás donde más difícil relación se manifiesta entre el feminismo y las tradiciones religiosas. Incluso esta relación entre islam y feminismo ha sido denominada como un oxímoron por algunas activistas, como la erudita y activista iraní Moghissi (Ramírez).

\section{Origen de la formación de murchidat: las reformas del plano religioso en marruecos}

La primera promoción de murchidat se graduó en 2005. Al programa formativo diseñado tanto para mujeres como para hombres, se presentaron ese año más de 1.000 solicitudes de los cuales 745 fueron hombres y 515 mujeres. En un primer momento se seleccionaron 100 mujeres, de las cuales, tras la entrevista inicial, sólo accederían 50 a los estudios (Rausch).

A pesar de que este curso se inició en 2005, algunos autores adelantan el comienzo de las reformas en la política religiosa marroquí a los primeros días tras la subida al trono del actual monarca, con la publicación de cuatro memorandos dictados en junio del 2000, difundidos por el Ministerio de Asuntos Religiosos y centrados en el control de las autoridades religiosas (Zeghal). Los atentados de Casablanca del 16 de mayo del $2003^{3}$ «aceleraron las reformas y en cierta forma les ofrecieron una nueva legitimidad a ojos de la opinión pública» (Zeghal 282) y empezó a emerger el concepto de «seguridad religiosa o espiritual» (El Haitami, 2012). La política religiosa de Mohamed VI pretende ejercer un mayor control de la esfera religiosa, a través de la modernización de las estructuras religiosas arcaicas y del control de los agentes religiosos, así como de la integración, instrumentalización y control

3. Ver noticia en <<http://elpais.com/diario/2003/05/17/internacional/1053122421_ 850215.html >>, consultada el 18-08-2014. 
de lo religioso en todas sus esferas, con una mayor concentración del poder religioso en torno al monarca (Regragui).

Con el nombramiento, el 7 de noviembre del 2002 de Ahmed Tawfiq, actual ministro de Asuntos Religiosos, se consiguieron poner en marcha las reformas anunciadas en el año 2000 y paralizadas bajo mandato del anterior ministro. Así, «se rompía con el estilo de (Abdelkadir Alaui) Mdeghri, diplomado en Dar al-Hadiz y al que se acusaba de connivencia con los salafíes» (Zeghal 284). Ahmed Tawfiq es conocido en Marruecos por su pertenencia a la Tariqa o Cofradía Qadiria Boutchichiya, además es un reconocido escritor e historiador. Con su nombramiento se rompe la práctica anterior donde todos los ministros encargados del Ministerio de Asuntos Religiosos provenían del ámbito religioso (Dirèche).

El Ministerio de Asuntos Religiosos, a través de su página de internet ${ }^{4}$, establece una relación de hechos desde 1999 a la actualidad bajo la denominación «cronología del campo religioso de 1999 a 2015». En este listado se recogen cada dahir, o texto legislativo promulgado directamente por el Rey, que reforma la propia estructura, funciones y competencias del Ministerio, propone nombramientos ministeriales y modifica las funciones y composición de la máxima estructura gubernamental religiosa ligada al Rey, el Consejo Superior de los Ulemas. También se enumeran cronológicamente otros hitos de la política religiosa bajo el reinado de Mohamed VI, desde el establecimiento del control de la formación de imanes y murchidat, o la reforma de la institución religiosa de Dar al-Hadiz, y la creación de diferentes premios en materia religiosa. Se ponen a disposición del lector los recursos económicos destinados a sufragar esta política, las dotaciones para peregrinos, para la creación de nuevas mezquitas y la financiación del personal administrativo y funcionario religioso.

La mujer experta en ciencias religiosas pasará a estar presente en muchos de los estamentos de la burocracia religiosa tras las reformas emprendidas, convenientemente anunciadas por el rey en los discursos de las sesiones de apertura de los trabajos del Consejo Superior de Ulemas. Mohamed VI utiliza las sesiones inaugurales de los encuentros de ulemas para anunciar las reformas y las líneas generales de la que a todas luces se muestra como una nueva política religiosa. Así, con motivo del encuentro de los miembros del Consejo Superior y de los consejos provinciales de ulemas en Casablanca el 30 de abril de 2004, el monarca dio publicidad a las primeras medidas adoptadas en lo que se autodenominó «política de proximidad». Cuatro años más

4. <<http://habous.gov.ma/fr/chronologie.html >>, consultado el 8-07-2015. 
tarde, en otro encuentro de ulemas en Tetuán, 27 de septiembre de 2008, presentó las bases de un ambicioso programa formativo para reforzar la enseñanza religiosa no sólo para el nuevo funcionariado religioso graduado en Dar al-Hadiz sino para acometer la difícil tarea de dar formación continua a los imanes, predicadores y resto de categorías religiosas que ya estaban ejerciendo en cualquier centro religioso del país.

Además de situar a la murchida en las mezquitas, instruyendo a otras mujeres, la administración marroquí pasa a integrar a las mujeres en otras estructuras. Esta suerte de «feminización del Estado» fue planteada al máximo responsable de la Dirección de Mezquitas en el Ministerio de Asuntos Religiosos, en una entrevista realizada en octubre del 2014, que negó tal término desmintiendo tal hecho.

A partir de la publicación del dahir de abril de 2004, en el que se decreta la reestructuración de los consejos de ulemas, aumentándolos y creando secciones por prefecturas además de la introducción en los mismos de mujeres, alimat, estudiosas de la religión, doctoras y profesoras de las universidades del país, los consejos de ulemas locales pasan a estar bajo tutela directa del rey y crece su número de 19 a 30. En 2004, estas estructuras abrieron sus puertas a 36 mujeres (El Haitami, 2013). Una de ellas, Fatteouma Kabbaj, pasaría a ocupar, por vez primera para una mujer, un puesto en el recién reformado Consejo Superior de Ulemas.

Otra de las cuestiones importantes en las reformas anunciadas por el monarca alauí fue la reestructuración de la institución encargada de garantizar la formación de los funcionarios estatales religiosos, Dar al-Hadiz alHassaniyya. Este centro fue creado por Hassan II, en 1964, con el propósito de formar a ulemas, «insistiendo en el retorno a la Sunna, (tradición del Profeta, de sus hechos, dichos y gestos) para legitimar su propia genealogía» (Zeghal). Con la reforma de la institución se intenta limpiar la imagen de la enseñanza religiosa en el centro al que se le acusaba de enseñar doctrinas islamistas (Rosenberg).

El nuevo decreto publicado el 24 de agosto del 2005 (Benyahya) reestructuró la institución superior haciéndola depender directamente del Ministerio de Asuntos Religiosos, se especifican los órganos administrativos, las funciones y el currículo docente del centro. Se estableció como prioritario que el establecimiento impartiera la formación continua a los imanes, predicadores y mujeres guías espirituales así como servir de referencia internacional en el estudio del pensamiento islámico, el estudio comparado de las religiones, 
la lengua, la jurisprudencia islámica o fiqh, y el rito maliquís (Zeghal). En este último punto, la página de internet del Ministerio de Asuntos Religiosos recoge las noticias de la apertura a extranjeros de la formación religiosa marroquí en Dar al-Hadiz ${ }^{6}$ desde su remodelación. De Malí, Guinea Conakry, Costa de Marfil, Túnez y Francia eran originarios los primeros candidatos que ya se beneficiaron de la formación religiosa ideada por la administración marroquí.

Atendiendo a la entrevista con el máximo responsable de la Dirección de Mezquitas en el Ministerio de Asuntos Religiosos, el señor Derouiche Abdelaziz, el número de plazas destinado a la formación de murchidat en la institución académica se amplió de 50 a 100 vacantes anualmente. En la entrevista el informante destacó la importancia de la puesta en marcha, desde junio del 2014, del Plan de Apoyo a la Orientación Religiosa a Nivel Local, donde, entre otras medidas, se recoge el refuerzo a las tareas de la murchida en el programa de lucha contra el analfabetismo cifrando en más de 5.000 las mezquitas beneficiadas por este plan desde su lanzamiento.

\section{Currículo formativo de las nuevas mujeres, guías religiosas, en Dar al-Hadiz}

Los requisitos para la admisión al curso de formación para estudiantes marroquíes en la institución superior en Rabat para formar parte de los puestos de trabajo en la administración religiosa marroquí son similares para hombres y mujeres: no ser mayor de 45 años, poseer un título universitario expedido en Marruecos, tener nacionalidad marroquí y saberse de memoria el Corán. Para los hombres aspirantes a la formación de murchid el requisito de conocimiento del Corán es íntegro mientras que para las estudiantes únicamente es imprescindible memorizar la mitad del Libro. Se valora poseer las mejores notas de su promoción y se debe pasar una entrevista previa. El curso tiene una duración de un año dividido en dos semestres y las clases son mixtas. El temario impartido por profesores universitarios, principalmente de la Universidad de Rabat, es común para todas las categorías pero sólo las aspirantes a murchidat, deben cursar la asignatura de «Fiqh al-Mara» o jurisprudencia de la mujer, impartida por la profesora Hanan Bin Sukrun, con la frecuencia de 2 horas semanales de un total de 60 anuales. Esta asignatura, detallada en el

5. Una de las escuelas jurídicas del islam, fundada por Malik Ibn Anas (711-796).

6. Dahir n. ${ }^{\circ} 1474.06$ sobre el número de estudiantes extranjeros susceptibles de integrarse en la formación fundamental específica en Dar al-Hadiz en $<$ http://habous.gov.ma/fr/ chronologie.html >>, consultada el 8-07-2015. 
plan de estudios de Dar al-Hadiz, recoge, según su director académico, el doctor Hassan Ibn Said, los fundamentos de la jurisprudencia islámica relativos a la mujer. En el primer semestre hay una aproximación desde la doctrina, con el estudio de los preceptos religiosos como la oración, el ayuno, la peregrinación y la limosna. Posteriormente, el temario de la asignatura avanza sobre el estudio de las leyes que regulan las relaciones sociales o Muamalat centrándose en la mujer en el medio social. También se estudia la jurisprudencia islámica referida a la vestimenta y el adorno de las mujeres, y se insta su participación en la vida social y política.

Con 20 horas lectivas, en el segundo semestre de la materia, se recogen los conceptos relativos a los derechos jurídicos económicos de la mujer dentro de la familia, la dote y pensión alimenticia que el marido debe a la mujer tras el divorcio, y el derecho de la administración de la mujer sobres sus bienes propios. Se recoge como última cuestión la autoridad del marido para gestionar los bienes de su mujer.

El resto de materias que conforman el curso de formación de murchidat que se realizan en la institución de Rabat versan sobre Corán y su interpretación, recitación del Corán, Sunna y Hadices o dichos del profeta, historia del mundo islámico, fiqh o jurisprudencia islámica, preceptos del imanato, preceptos del sermón o jutba, lengua árabe, biografía del profeta, sufismo y rito ashari $^{\dagger}$, sistema jurídico nacional e internacional, fundamentos de la escuela maliquí con 80 horas lectivas, sociología de las religiones y otras materias no relacionadas con la religión como clases de informática y nuevas tecnología, con 160 horas lectivas, geografía, mediación y técnicas para resolución de conflictos y psicología. Aunque inicialmente se programó una asignatura deportiva, finalmente se eliminó por falta de tiempo (Rausch). En total, el curso de un año escolar de duración consta de 20 materias y un total de 1260 horas de instrucción, divididas en dos semestres.

El desarrollo de un programa formativo como el que reciben las murchidat se fundamenta, según los documentos obtenidos en Dar al-Hadiz, en tres pilares: la Constitución marroquí del año 2011, y en concreto se hace referencia al artículo 41, el discurso real en la inauguración de la sesión del Consejo

7. Escuela teológica fundada por Abu al-Hassan al-Asharí en el siglo X, que propugna el uso de la razón y la teología conjetural para defender la fe.

8. Los documentos originales en árabe fueron entregados por el director académico, Doctor Hassan Ibn Said, al que damos las gracias por su amabilidad y cortesía durante el encuentro. 
Superior de los Ulemas en Tetuán el 27 de septiembre del 2008 antes mencionado y La guía del imam, orador y predicador ${ }^{9}$.

El primer ítem en el que se asientan los contenidos del programa formativo a murchidat es el máximo texto legislativo del estado marroquí y concretamente el artículo 41 donde se recoge que el rey es garante de la libertad de la práctica religiosa y ostenta el título de Emir de los Creyentes. Podemos expresar que esta constante es la base del modelo de islam marroquí que fundamenta la reforma religiosa y por tanto, las nuevas categorías profesionales religiosas donde se encuentra la figura de la murchida.

El otro elemento fundamental en los documentos del plan de estudios son las palabras del discurso del rey en 2008 donde, a modo de resumen, se detallan las reformas emprendidas por la monarquía en el plano religioso desde que estás se pusieran en marcha en el año 2000.

Por último, La guía del Imán, orador o jatib y predicador, editada íntegramente en árabe y elaborada por varios ulemas y miembros del propio Ministerio de Asuntos Religiosos es el manual de referencia, a modo de filosofía y base doctrinal, de las asignaturas que componen la formación a murchidat, murchidines e imanes en Dar al-Hadiz. No obstante, y como se menciona en su introducción, el libro pretende ser la herramienta básica para la conformación de un único mensaje doctrinal religioso en todos los centros piadosos del país y, por tanto, que pueda ser utilizada por los numerosos líderes espirituales a lo largo del todo el territorio marroquí.

Según el trabajo realizado por Rausch, este manual se editó por primera vez, con 50 ejemplares, en el momento de la creación del programa de formación para murchidat e imanes en 2005, «de forma que estos funcionarios religiosos dispusieran de un guía en el ejercicio de sus funciones» (Rausch, 2010) y a partir del 2007, fecha de la primera edición, se distribuyó a todos los centros religiosos del país.

Los objetivos de la edición y distribución de esta guía, de modo más especifico, según se recoge en la introducción de la misma son: establecer las bases del mantenimiento de las mezquitas como lugares sagrados, garantizar la tranquilidad de visitantes y fieles, orientar a los imanes, oradores y predicadores para alcanzar unos objetivos comunes, profundizar en la comunicación entre todos los profesionales religiosos (incluyendo a todos los consejeros y/o líderes religiosos del país) con el fin de servir a los intereses de la nación.

La Guía del Imán se divide en seis capítulos y esgrime la urgente necesidad de contar con un manual de referencia para la unidad doctrinal del país,

9. Título original en árabe دليل الإمام و الخطيب و الو اعظ 
dotando de forma y contenido las funciones del imanato, a los predicadores y oradores, alentando a los jefes o líderes religiosos a profundizar en su conocimiento religioso, aportándoles un corpus doctrinal, unificando conceptos y metodología en los campos de la predicación y la oración.

Según la página de internet del ministerio son cuatro las bases o pilares doctrinales del manual; el rito asharí, la escuela jurídica maliquí, el sufismo y la institución de la monarquía con el título de Comendador de los Creyentes como un pilar de las bases religiosas y políticas del estado marroquí.

Así el enfoque integral de la religión, el papel de la predicación en el crecimiento nacional, gestión de la religión en el contexto internacional, el respeto por la práctica religiosa y el juicio, modelos de ritual religioso y los sermones del viernes y el papel del predicador serán los títulos de los seis capítulos en los que se divide la guía.

El capítulo primero describe las bases o pilares doctrinales y detalla la necesidad de asegurar la unidad doctrinal del país. En el segundo capítulo, se pide poner énfasis en el desarrollo espiritual del proceso de la predicación y la orientación de los fieles con el fin de inculcar en ellos los valores de la espiritualidad. La tercera sección insiste en el respeto de los principios de convivencia y los derechos fundamentales de los no musulmanes que viven en países musulmanes y la adhesión a todos los convenios y tratados internacionales que no son de oposición a la sharia o ley islámica. El capítulo cuarto hace hincapié en el hecho de la elección de la escuela maliquí como el único ritual religioso oficial del estado y marco legal, guiado en particular por la necesidad de asegurar la unidad y la cohesión de la nación y de evitar toda forma de discordia. Se articulan en el capítulo quinto los modelos de culto religiosos y las prácticas que están actualmente en vigor en Marruecos, la mayoría de los cuales se basan en su legitimidad religiosa en general y los objetivos científicos y pedagógicos. En el sexto y último capítulo se recomienda que el papel del predicador se ajuste a una serie de reglas objetivas, para incitar a la gente a la moderación y el equilibrio, fomentar ciertas formas de reuniones y el amor hacia los demás y promover el positivismo en lugar del nihilismo.

Tanto el programa de formación como el manual se concentran en concretar y clarificar los términos religiosos desde la perspectiva real y del gobierno de Marruecos, mientras que proveen el significado para inculcarlo en los nuevos agentes de transmisión y a la población a la que va dirigido. 


\section{Una nueva categoría profesional: la murchida}

En el boletín oficial del Reino de Marruecos n. ${ }^{\circ} 5430$ del 15 de junio del 2006 se aprueba el modelo tipo de contrato que se celebra entre el estado y los imanes, las murchidat y los murchidines.

El objeto de este documento es fijar la misión o funciones a desarrollar por los nuevos funcionarios religiosos una vez finalizado el curso de formación. En el texto se diferencia entre la misión reservada únicamente a los imanes que se describe como:

Asegurar como iman las cinco oraciones diarias y la oración del viernes, contribuir a la mejora de los sermones del viernes, llamar a la oración, si se diera el «caso»

El cometido común para los imanes, las murchidat y los murchidines serán:

Dar cursos en diferentes ciencias islámicas, de predicación y de sensibilización para transmitir los preceptos de la sharia o ley islámica, enseñar el «santo Corán». Contribuir a la formación continua de imanes o de murchidat y otros agentes religiosos. Favorecer la preservación de la unidad religiosa de la sociedad y de su cohesión. Dar cursos de alfabetización, contribuir a la actividad cultural y social en la mezquita. Resolver los conflictos entre las personas que lo soliciten, supervisar todas las actividades religiosas educativas o culturales organizadas en el seno de la mezquita, garantizar el mantenimiento de la mezquita y preservar cualquier actividad fuera del marco religioso, de acuerdo con las directivas de la autoridad gubernamental del Ministerio de Asuntos Religiosos.

El contrato se establece por una duración indeterminada. Además, los nuevos funcionarios serán destinados a lugares próximos al domicilio familiar. También existen becas mientras se realiza la formación en la institución académica de Rabat que ascienden a 2000 dirhams mensuales. De este texto legislativo extraemos que los campos de acción de estos cuadros administrativos religiosos son la mezquita y los centros religiosos pero, también sabemos por las entrevistas realizadas ${ }^{10}$ que las murchidat también actúan en centros penitenciarios, hospitales y centros de acogida de menores. De esta forma, las murchidat se definen no sólo como guías religiosas encargadas de las enseñanzas islámicas sino que desarrollan también tareas como consejeras, mediadoras en conflictos y hasta de trabajadoras sociales.

Por último cabe señalar, que con la promulgación de este dahir, se dejan claras las funciones reservadas a cada categoría profesional y se cierra de esta

10. Entrevista realizada en la mezquita de Fuenlabrada en Madrid, en julio del 2014 a una murchida marroquí miembro de la delegación religiosa enviada a España por el Ministerio de Asuntos Religiosos con motivo del mes de Ramadán. 
forma la controversia surgida a raíz de que los medios de comunicación internacionales denominarán a las murchidat marroquíes como las nuevas imanes en femenino (Dirèche). Algunos artículos periodísticos asimilaron las nuevas categorías con la activista pakistaní asentada en Estados Unidos, Amina Wadud, que se atrevió a liderar la oración del viernes ante una congregación mixta musulmana. Esta similitud llevó a que el Consejo Superior de Ulemas dictara una fetua, directriz sobre la jurisprudencia islámica, el 26 de mayo de 2005, explicando que las mujeres murchidat no pueden ser imanes, ni dirigir las oraciones ni dar el sermón de los viernes en la escuela maliquí (Dirèche).

\section{Construyendo el feminismo islámico en la voz de las nuevas generaciones de murchidat}

El actual momento marroquí se caracteriza por lo que algunos autores califican como un renacimiento religioso apoyado por mujeres que aparentemente podría tener mayores posibilidades de emancipación (Ali, 2014). Esta emancipación vendría dada dentro del contexto de la pedagogía islámica y de un formación estructurada y dirigida por el paradigma gubernamental pero que, a través del discurso y la praxis de las mujeres involucradas resultaría emancipatoria y de progresiva potencial capacidad liberadora. De esta forma, esbozamos la siguiente pregunta ipuede un programa estatal ideado desde las altas esferas gubernamentales, en el que participan graduadas universitarias con una religiosidad latente y un discurso más o menos reformador sobre el papel de la mujer en las tradiciones islámicas y su transmisión, ser analizado como un movimiento islámico reformista de capacidad femenina?

Para contestar a esta difícil cuestión es preciso explorar el lugar que puede ocupar en un contexto de estructuras y entramados religiosos mayoritariamente e históricamente masculino una formación a mujeres como agentes sociales, religiosas y de adoctrinamiento en mezquitas y, una vez conocido este espacio, valorar si puede considerarse como movimiento emancipatorio que da lugar a una agencia o capacidad de acción de la mujer como individuo crítico que desarrolla su tarea en un marco de cierta libertad, o si la falta de tal margen de maniobra, las convierte de modo reduccionista en agentes «islamizantes» controladas por la administración. Esta ardua tarea subyace en el análisis del discurso y las prácticas de estas estudiantes y mujeres formadas como líderes socio-espirituales que a pesar de encontrarse ubicadas en un entramado religioso burocrático suponen un atisbo de revolución y emancipación en el status quo del género femenino en la sociedad magrebí y en la política secular del islam. También tomamos prestado para apoyar nuestra hipótesis los conceptos de agencia social dócil de Saba Mahmood sugiriendo 
que «consideremos la agencia social no como un sinónimo de resistencia en las relaciones de dominación, sino como una capacidad de acción que se habilita y crea en relaciones de subordinación históricamente específicas» (Mahmood, 2008).

Este argumento de Mahmood es utilizado en su relato etnográfico de la actividad urbana de mujeres en la mezquita en el movimiento de renacimiento islámico en El Cairo, Egipto. Así, la idea de participación de las mujeres egipcias en el movimiento islámico como agente dócil puede ser extrapolada a la experiencia marroquí que aquí planteamos.

También presentamos, a continuación, apoyando nuestra respuesta a la pregunta planteada, algunas conclusiones extraídas del análisis del discurso de las estudiantes entrevistadas en el trabajo de campo realizado en Rabat, Marruecos, en octubre del 2014.

Las cinco alumnas de Dar al-Hadiz entrevistadas pertenecen a la promoción del curso 2014-2015. Todas expresaron cómo libremente habían decidido convertirse en transmisoras del mensaje islámico a pesar de haber estudiado en la universidad diferentes licenciaturas (estudios ingleses, biología o historia) y no haber elegido en su momento los estudios religiosos.

La elección de estos estudios partía de una inquietud común: «dar a conocer su religión ya que existen muchas personas desconocedoras de las correctas prácticas religiosas». Todas veían en la formación de murchidat una forma de transmitir lo que ellas consideraban la «verdadera religión», o las formas correctas de practicar el islam, ya que describieron como incorrectas algunas de las formas «populares» de vivir la religión musulmana. En este sentido, sirva como ejemplo lo novedoso que para ellas resultó encontrar el sufismo dentro de las materias estudiadas. Al preguntárseles por ello, todas afirmaron que habían descubierto gracias al profesor que impartía esta materia, que el sufismo forma parte del islam marroquí, que aún «no siendo la ortodoxa, forma parte de la singularidad del pueblo marroquí». El profesor encargado de la docencia de la asignatura es un alto cargo ligado al gabinete del propio ministro de Asuntos Religiosos, Ahmed Tawfiq.

El compromiso social con la situación de las mujeres en Marruecos también apareció en todas las entrevistadas. Argumentaron la necesidad de enseñar no sólo la praxis del islam entre las mujeres marroquíes sino también enseñarles a leer y escribir, afirmando que existía un gran porcentaje de mujeres en las zonas rurales que son analfabetas y que esto representa un gran problema para su desarrollo. En esta misma línea, Asma Lamrabet, reconocida 
activista feminista y escritora marroquí ${ }^{11}$ reconoció que le constaba cómo el trabajo de las murchidat por todo el territorio marroquí ha reducido la tasa de analfabetismo entre las mujeres y que ese dato podría considerarse como un éxito de la iniciativa. Sin embargo, matizó que el programa de formación desde su punto de vista no proponía un islam reformista, ni incorporaba una visión femenina sino patriarcal.

En este mismo sentido, las estudiantes entrevistadas en Dar al-Hadiz, respondieron a la pregunta sobre las enseñanzas religiosas recibidas y el papel de la mujer en la religión musulmana con una anécdota sobre la diferenciación y complementariedad entre los seres humanos, según ellas, aludiendo a las «diferencias naturales de fuerza y constitución entre hombre y mujer, atribuyendo a cada uno de ellos tareas y trabajos diferentes según éstas» pero afirmando tajantemente «la necesidad de que un hombre pueda ayudar a la mujer en los trabajos físicos que requieran de mayor fuerza y destreza ya que sólo el hombre puede tener estas cualidades al igual que sólo las mujeres pueden ser madres y esposas». Para las estudiantes sólo existen diferencias físicas que hacen diferentes a los sexos y les atribuyen heterogéneos roles sociales pero que a su vez les hacen necesarios y complementarios unos a otros. En cuanto a la relación de los sexos en la religión, expresaron el concepto de igualdad tajantemente con la expresión «ante Dios y en el Islam el hombre y la mujer son iguales».

De las palabras de las futuras murchidat podemos extraer algunas ideas atribuidas a la hermenéutica del movimiento femenino islámico como la de tawhid, con el significado de unidad en la creación en términos de complementariedad en oposición a la estratificación de las criaturas según sus cualidades o atributos y el de adl o justicia, como concepto cosmológico y ético basado en un equilibrio entre los atributos complementarios (Valcárcel y de la Fuente). El concepto claramente extraíble del discurso de las estudiantes, es el de principio de igualdad o musawa. El término igualdad es clave en la definición del movimiento feminista islámico o musulmán.

Según la socióloga Zahra Ali (2014), en la revisión y reforma del principio de igualdad entre los sexos y la justicia social en los textos sagrados de la religión musulmana, podemos encontrar la base de las diferentes posturas del actual movimiento feminista islámico tanto en los países árabes e islámicos como a nivel transnacional. Así, Ali presenta las diferentes corrientes según la centralidad de la relación con los textos, la primera postura la califica

11. Entrevista mantenida en su oficina en el Centro de Estudios de la Mujer en el Islam en Rabat. 
como «reformista tradicional», la segunda como «reformista radical» y la última como «reformista liberal». La postura tradicional afirma que hombres y mujeres son iguales en la religión pero que sus particularidades biológicas les llevan a asumir roles y derechos y deberes diferentes. Aluden a las fuentes religiosas esgrimiendo que el estatus de la mujer está claramente definido en éstas. La «reformista radical» se basa en el pensamiento reformista islámico con impronta radical y crítica que pregona una revisión no sólo de la lectura del Corán y la Suna sino de la jurisprudencia islámica -fiqh-y a través del iytihah, o esfuerzo interpretativo, la creación de un nuevo estatus reformando las lecturas patriarcales de los textos sagrados. Por último, nos encontramos con la corriente reformista liberal, que según el texto de Ali, es la postura defendida mayoritariamente por las feministas musulmanas socializadas en jerarquías religiosas.

De esta forma, podemos asemejar las palabras del discurso de las estudiantes con algunos conceptos expresados por Ali en la teoría feminista más tradicional. Las futuras murchidat aluden a las diferencias biológicas de los seres humanos, a los roles divinos y sociales otorgados a los géneros pero asumen y reivindican el principio de igualdad divino como ocurre en la propuesta feminista «reformista tradicional» (Ali, 2014). No encontramos explícitamente en las palabras de las futuras murchidat una reflexión más profunda sobre otros términos que encontramos en los conceptos asociados al movimiento del feminismo islámico, como puede ser la hermenéutica del Corán con perspectiva de género crítica para el desarrollo de una teología de la liberación de la mujer o el concepto del Califato, entendido como la responsabilidad individual frente a Dios de ser su representante en la tierra con la misión de desarrollarse en plenitud con el fin de contribuir al mejoramiento de la creación (Lamrabet). Es más, en una entrevista mantenida con el máximo responsable de la Dirección de Mezquitas en la sede del Ministerio de Asuntos Religiosos en Rabat, a propuesta de la entrevistadora, éste rechazó el concepto de feminismo en el islam al serle planteado este término a propósito de la formación a mujeres. Esta opinión es similar a la recogida por autoras como Badran, Ali y Mahmood, que recogen una idea muy extendida en algunas esferas de las sociedades musulmanas: que el concepto de feminismo es un concepto occidental, o de epistemología occidentalocéntrica (Adlbi) alejado de la tradición islámica.

Así, si tenemos en cuenta que una de las reivindicaciones de las exegetas del movimiento feminista musulmán desde 1990 es el acceso de las mujeres a puestos religiosos (Badran) podríamos también encuadrar el acceso de la 
mujer a la profesión de las murchidat en la esfera pública de la religión como un vínculo más de esta nueva figura con el feminismo islámico.

Cabe destacar de las palabras recogidas en las entrevistas de Dar al-Hadiz el entusiasmo y la dedicación en la transmisión del saber islámico a otras mujeres que esbozaron las estudiantes. Esta idolatría por la enseñanza religiosa les llevó, a cada una de ellas, a elegir libremente la profesión de guía religiosa. La formación de la mujer en altos estudios de la ciencia islámica como es el curso de un año de duración para convertirse en murchida, es a su vez, otra semejanza al movimiento feminista islámico. Según Zahra Ali, la emancipación de la mujer puede darse a través del conocimiento profundo de la ciencia islámica y por tanto, a través del campo de la religión. La entidad islámica representa para estas estudiantes un síntoma liberador, una profesión escogida y tal vez, un cambio sustancial, a través de la educación, en la condición, en algunos casos, de subordinación o desigualdad, de la mujer marroquí.

Por último, cabe reseñar que el atuendo utilizado uniformemente por las alumnas del curso de formación a murchidat 2014-2015 es el hiyab islámico. Si bien atendemos a lo expuesto en la obra de Katherine Bullock, el uso del velo islámico puede atenerse a múltiples significados políticos, económicos, culturales y no sólo religiosos, sin embargo, en esta experiencia nos acercamos más al razonamiento expuesto por Saba Mahmmood en su investigación sobre el movimiento piadoso de mujeres en las mezquitas de El Cairo, donde el uso del hiyab respondía a conceptos como «piedad y pudor» y las protagonistas de su investigación definidas como «sujetas piadosas con mayor conocimiento religioso» (Mahmood, 2011). De esta forma, las estudiantes murchidat con el uso uniforme del velo islámico también construyen una imagen externa de su religiosidad latente y de una subjetividad religiosa que configura su estatus social y su condición de letradas en ciencias islámicas, así como puede también ser «un constructor de las relaciones y la identidad de género de estas mujeres» (Valcárcel y de la Fuente).

A modo de conclusión recuperamos el objetivo inicial de este artículo, que no es otro que mostrar como un programa de formación superior gubernamental viene a visibilizar una tradicional transmisión de la religión musulmana por parte de las mujeres. La figura de la murchida y su codificación dentro de la administración marroquí puede otorgar posibilidades laborales y cierta emancipación, a través de la religión, a jóvenes estudiantes universitarias, transformándolas en educadoras y líderes comunitarias. También hemos considerado en esta investigación en forma de hipótesis, al movimiento de las murchidat como una suerte de corriente de pedagogía islámica a mujeres que 
podría considerarse como una tendencia liberadora a través del conocimiento de la religión. A su vez, nos planteamos ciertas similitudes entre los discursos de las estudiantes aspirantes a murchidat y la teoría feminista reformista tradicional de la autora Zahra Ali así como hemos utilizado los conceptos de la agencia dócil de Saba Mahmmood.

Finalmente, no pretendemos encasillar los resultados del trabajo de campo sobre la formación de murchidat en una tipología determinada, ni otorgar denominaciones estancas, sino únicamente esclarecer y presentar una nueva categoría profesional con la importancia que ésta puede llegar a tener en toda la sociedad del país árabe y, sobre todo, en las comunidades en las que actúa y en la situación de la mujer marroquí. Es posible que estemos ante una nueva autoridad religiosa en las estructuras del islam, que únicamente por el hecho de ser mujer represente un modelo a seguir para otras féminas. Estas intelectuales, comprometidas y concienciadas con un modelo nacional de religión, aunque ideado desde las altas esferas del gobierno marroquí, pueden representar un islam en femenino, sin llegar a plantear posturas radicales de reinterpretación del mensaje coránico con perspectiva de género, pero mostrando en su propia imagen cómo la mujer puede desempeñar, prácticamente, las mismas funciones que un hombre en el ámbito público de la religión. El trabajo de la murchida aporta a la agencia femenina cierto atisbo liberador y puede producir cambios en el estatus de la mujer en su reivindicación de un espacio en las estructuras religiosas del islam en Marruecos. Tal vez, mostrando así la feminización de la administración marroquí o, más aún, un feminismo islámico de estado que a su vez conlleve una reislamización de la sociedad marroquí con impronta claramente nacional para legitimar al monarca como máxima autoridad en la figura del Emir o Comendador de los Creyentes.

\section{Referencias bibliográficas}

AdlBI SibAI,Sirin. «Colonialidad, feminismo e Islam».Viento Sur 122. (2012): 57-67.

Ali, Zahra. Féminismes islamiques. Paris: La Fabrique éditions, 2012.

Ali, Zahra.»Feminismos islámicos». Tabula Rasa (2014): 123-137.

BADRAN, Margot. «Feminismo islámico en marcha». Clepsydra. Revista de Estudios de Género y Teoría Feminista (2010): 69-84.

BANO, Masooda y Hilary Kalmbach. Women, Leadership, and Mosques: Changes in Contemporary Islamic Authority. Leiden: Brill, 2011.

Benyahya, Mohamed. Gestion des Mosquées et des Préposés Religieux. Rabat: Remald, 2014. 
BULLOCK, Katherine. Rethinking Muslim women and the veil. Londres: The International Institute Of Islamic Thought, 2002.

DARIF, Mohamed. Monarchie marocaine et acteurs religieux. Casablanca: Afrique Orient, 2010

DesRues, Thierry y Juana Moreno Nieto. «Cambios en la condición de la mujer marroquí: ¿espejismo o realidad?». (IESA) Informes y documentos de trabajo. Enero 2007.

DIRĖCHE, Karima. «Les Murchidât au Maroc. Entre islam d'État et islam au féminin». Revue Mondes Musulmans Méditerranée 128 (2010): 99-111.

EL HAITAMI, Meriem. «Restructuring female religious authority: state-sponsored women religious guides (murshidat) and scholars ('alimat) in contemporary morocco». Mediterranean Studies 20 (2012).

El Haitami, Meriem.»Women in Morocco: political and religious power». OpenDemocracy (2013). 14 de julio del 2015.

LAmrabet, Asma. El Corán y las mujeres: una lectura de liberación. Madrid: Al Fanar Traductores, 2010.

MAHMOOD, Saba. «Teoría feminista y el agente social dócil: algunas reflexiones sobre el renacimiento islámico en Egipto». Descolonizar el Feminismo: Teorías y Prácticas desde los Márgenes. Madrid: Cátedra, 2008: 165-222.

MaHmoOD, Saba. Politics of Piety: The Islamic Revival and the Feminist Subject Princeton University Press, 2011.

Mohanty, Chandra Talpade. «Bajo los ojos de Occidente. Academia feminista y discurso colonial». Descolonizar el Feminismo: Teorías y Prácticas desde los Márgenes. Cátedra: Madrid, 2008.

Mohanty, Chandra Talpade, Anna Russo y Lourdes Torres. Third World Women and the Politics of Feminism. Bloomington and Indianapolis: Indiana University Press, 1991.

RAMíREZ, Ángeles. «Libres, fuertes y mujeres: Diversidad, formación y prácticas de los feminismos islámicos». Feminismos en Antropología Nuevas Propuestas Críticas (2008): 21-37.

RAUSCH, Margaret. «Women Mosque Preachers and Spiritual Guides: Publicizing and Negotiating Women's Religious Authority in Morocco». Women Leadership and Mosques Changing Contemporanean Islamic Authority. Leiden. Brill 2011: 59-84.

REGRAGUI, Ismail. La diplomatie publique marocaine: une stratégie de marque religieuse ? Editions LHarmattan: Paris, 2013.

ROSENBERG, Joel. Inside the Revolution: How the Followers of Jihad, Jefferson, and Jesus Are Battling to Dominate the Middle East and Transform the World. Tyndale House Publishers: 2011. 
VALCÁRCEL, Mayra Soledad y Vanessa Alejandra de la Fuente. «Feminismo, identidad e Islam: encrucijadas, estrategias y desafíos en un mundo transnacional». Tabula Rasa (2014): 139-164.

ZEGHAL, Malika. Islam e islamismo en Marruecos. Edicions Bellaterra: Barcelona, 2000. 